\title{
A unique case of female pseudohermaphroditism with 21-hydroxylase deficiency and small supernumerary marker chromosome 7
}

\author{
WALID AL-ACHKAR $^{1}$, ABDULSAMAD WAFA ${ }^{1}$, MANAR ASSAAD $^{1}$, CHRISTIAN EHLERS $^{2}$ and THOMAS LIEHR ${ }^{3}$ \\ ${ }^{1}$ Department of Molecular Biology and Biotechnology, Division of Human Genetics, \\ Atomic Energy Commission of Syria, Damascus, Syria; ${ }^{2}$ Mitteldeutscher Praxisverbund Humangenetik, \\ Dresden; ${ }^{3}$ Jena University Hospital, Institute of Human Genetics, Jena, Germany
}

Received August 25, 2011; Accepted January 24, 2012

DOI: $10.3892 / \mathrm{mmr} .2013 .1349$

\begin{abstract}
Small supernumerary marker chromosomes (sSMCs) are present in $\sim 2.6 \times 10^{6}$ individuals worldwide. Concerning their clinical consequences as well as their chromosomal origin and shape, sSMCs are a heterogeneous group of derivative chromosomes; $70 \%$ of sSMC carriers are clinically normal. In the present study, we report on a female with mosaicism (45\%) of a de novo sSMC derived from chromosome 7 , in which the observed clinical signs do not correspond to comparable cases in the literature. She is clinically normal apart from problems in gender determination, a uterus without ovaries and an external penis, pointing overall towards an adrenogenital syndrome (AGS). 21-Hydroxylase deficiency (21-OHD) is the most common cause of AGS. A corresponding analysis for underlying mutations in the CYP21A2 gene revealed a homozygous mutation c.518T >A (p.Ile173Asn) inherited from both non-related parents. Overall, in this study, we report a unique case of female pseudohermaphroditism, classified as a simple virilization form of 21-OHD having an additional minuteshaped chromosome 7 [min(7)(:p11.1->q11.23:)]. Notably, AGS was due to a mutation in the CYP21A2 gene located on chromosome 6. This is a further example that detection of an sSMC does not always resolve the clinical case.
\end{abstract}

\section{Introduction}

Small supernumerary marker chromosomes (sSMCs) have been defined as structurally abnormal chromosomes that cannot be identified or characterized unambiguously by conventional

Correspondence to: Dr Walid Al-Achkar, Department of Molecular Biology and Biotechnology, Division of Human Genetics, Atomic Energy Commission of Syria, P.O. Box 6091, Damascus, Syria

E-mail: ascientific@aec.org.sy

Key words: small supernumerary marker chromosome 7, mosaicism, pseudohermaphroditism, congenital adrenal hyperplasia, 21-hydroxylase deficiency, CYP21A2 gene, molecular cytogenetics banding cytogenetics alone, and are (in general) equal in size or smaller than chromosome 20 of the same metaphase spread. As they are too small for their chromosomal origin to be considered by traditional banding techniques, molecular cytogenetic techniques (including array-based comparative genomic hybridization) are required for their characterization (1). sSMCs are found in approximately 4.4/100,000 newborns (2) and they are found in three different shapes: ring, inverted duplicated and centric minute (3). Partial trisomy 7 or partial monosomy 7 share some common clinical features, such as mental retardation, growth deficiency and finger abnormalities as well as eye and ear anomalies. In addition, certain patients present variable features, such as triangular face, high frontal hairline, high arched palate, clinodactyly and asymmetry of limbs (4).

Uniparental disomy (UPD), the abnormal inheritance of both chromosomes from only one parent, has been described for different human chromosomes. UPD can be associated with an sSMC as a result of an original trisomy with consecutive trisomic rescue (5).

Congenital adrenal hyperplasia $(\mathrm{CAH})$ is one of the most common autosomal recessive disorders, with an estimated carrier frequency of 1 in 50 (6), and is due to 21-hydroxylase deficiency (21-OHD), one of the enzymes required for the synthesis of cortisol in the adrenal cortex. Impaired 21-hydroxylase activity causes accumulation of steroid precursors, which then flow into biosynthetic pathways unaffected by the enzymatic block, resulting in the production of excess androgens. When androgens are over-secreted from the adrenal glands, the female fetus is virilized (7). Complete enzyme inactivation or low but measurable enzyme activity leads to the salt wasting (SW) form, 3-7\% residual enzyme activity leads to the simple virilizing type and more than $30 \%$ residual enzyme activity leads to the non-classic type (7). Approximately $75 \%$ of patients with classic 21-OHD have the SW form, which is associated with severe impairment of 21-hydroxylation of progesterone and 17-hydroxyprogesterone (17-OHP) (7).

The 21-hydroxylase gene, CYP21 (CYP21A2, OMIM No. 201910), is located on chromosome 6p21.3 within the HLA histocompatibility complex in close proximity to the highly homologous inactive pseudogene, CYP21P (CYP21A1P) $(8,9)$. Recombinations and conversions between CYP21A1P 
and CYP21A2 result in the generation of dysfunctional CYP21A2 alleles $(7,10)$. Approximately $90 \%$ of CYP21A2 mutations are a result of CYP21A1P-derived conversions and recombinations $(7,11)$. CYP21A2 genotyping can be useful in the diagnosis of $\mathrm{CAH}$ and can also predict the phenotype in $80-90 \%$ of cases $(12,13)$.

In this study, we present a female pseudohermaphroditism/ adrenogenital syndrome (AGS) case with a $45 \%$ mosaicism for a small supernumerary ring chromosome 7 associated with a homozygous mutation in the CYP21A2 gene.

\section{Materials and methods}

Case report. The patient is the sixth child of non-related parents. Her mother was 35 and her father 49 years of age when she was born. She is now 10 years old, $135 \mathrm{~cm}$ in height, and was referred to a cytogenetic analysis due to a gender determination problem in July 2009. She was born in the 37th week of gestation with a birth weight of $3,250 \mathrm{~g}$. She has a facial dysmorphism (triangular face, high frontal hairline, asymmetry of limbs (Fig. 1) and long fingers (Fig. 2). Her speech was delayed; her first words were not until 2 years of age, and her language skills were poor until 8 years, especially concerning her performances on the expressive side. She has a uterus without ovaries, dense hair distribution on her body (especially in the pubic area), a large genital vagina; the clitoris is very pronounced $(5 \mathrm{~cm}$ in length) and lift cornet. However, she does not have testes. A CT scan showed enlargement of the adrenal glands: left, $32 \times 7 \mathrm{~mm}$; right, $38 \times 8 \mathrm{~mm}$ (normal adrenal gland size is $14 \times 2 \mathrm{~mm}$ ) (Fig. 3). The bone mass densitometry (BMD) using the lunar prodigy advance system (manufactured by GE Healthcare; analysis version 13.20), measured at AP spin L1-L4 was $0.964 \mathrm{~g} / \mathrm{cm}^{2}$ with a Z-score of 2.1, which is significantly higher than normal limits for her age and gender. The bone age was 18 years. The ACTH level was $228 \mathrm{pg} / \mathrm{ml}$ (normal value $<63$ ), progesterone level was $5.35 \mathrm{ng} / \mathrm{ml}$ (normal value $<1.13$ ), $17-\mathrm{OH}$ progesterone level was $13.9 \mathrm{ng} / \mathrm{ml}$ (normal value $<2$ ), 17-ketosteroid level was $58.37 \mathrm{mg} / 24 \mathrm{~h}$ (normal value $<14$ ), $\delta-4$ androstendion level was $4.4 \mathrm{ng} / \mathrm{ml}$ (normal value $<1$ ), cortisol level was $5.6 \mu \mathrm{g} / \mathrm{dl}$ (normal value $<25$ ), testosterone level was $210 \mathrm{ng} / \mathrm{dl}$ (normal value $<100$ ), LH level was $2.2 \mathrm{mlU} / \mathrm{ml}$ in the follicular phase (normal value <11.6) and FSH level was $6.3 \mathrm{mlU} / \mathrm{ml}$ in the follicular phase (normal value $<11.3$ ).

Cytogenetics. Chromosome analysis using GTG-banding was performed according to standard procedures (14). A total of 100 metaphases analyzed from stimulated peripheral blood culture were analyzed. The karyotype was described according to the International System for Human Cytogenetic Nomenclature (15).

Molecular cytogenetics. Fluorescence in situ hybridization (FISH) using LSI SRY (Yp11.3) SpectrumOrange/CEP X SpectrumGreen probe (Abbott Molecular/Vysis, USA) and centromere specific multicolor FISH (cenM-FISH) was performed $(16,17)$. Subsequently, a centromere-near multicolor FISH (subcenM-FISH) probe set for chromosome 7 (18) was used to check for the presence of centromere-near euchromatic material on the small marker chromosome. The

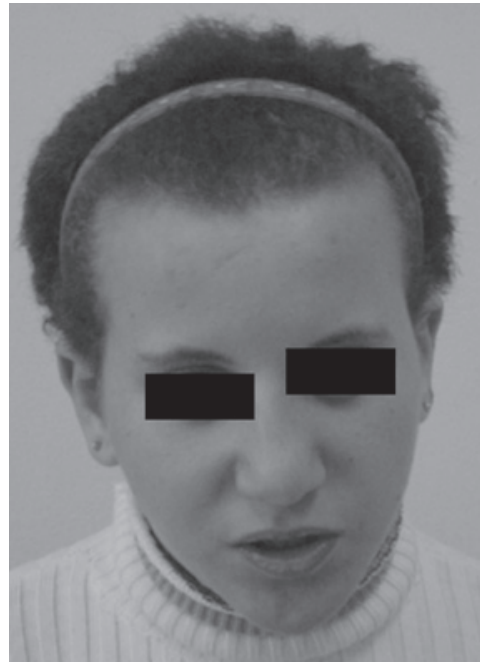

Figure 1. Facial appearance of the patient.

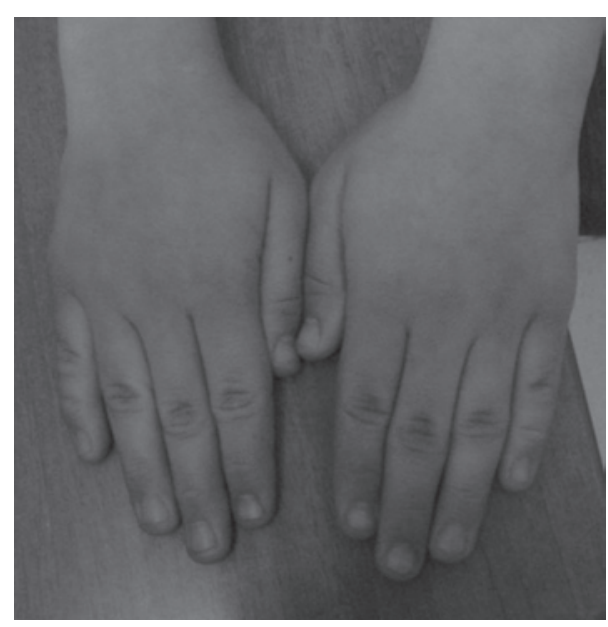

Figure 2. Long fingers of the patient.

applied subcenM-FISH probe set consists of 2 partial chromosome painting (pcp) probes, 1 for the long and 1 for the short arm of chromosome 7, both centromere-specific probes for chromosome 7 (D7Z1; Abbott Molecular/Vysis) of 2 BAC probes (RP 11-10F11 specific for 7p11.2 and RP11-3N2 located in $7 \mathrm{q} 11.21)$. Furthermore, a commercially available probe for the ELN-gene in 7q11.23 together with a control in 7q31 (D7S486, D7S522) was used to characterize the sSMC in further detail. A total of 20 metaphase spreads were analyzed, each using a fluorescence microscope (AxioImager.Z1 mot; Zeiss) equipped with appropriate filter sets to discriminate between a maximum of 5 fluorochromes and the counterstain 4',6-diamino-2-phenylindole (DAPI). Image capturing and processing were carried out using an ISIS imaging system (MetaSystems, Altlussheim, Germany).

\section{Results}

The karyotype determined by GTG-banding identified was mos 48,XX,+mar1x2[1]/47,XX+mar1[45]/46,XX[54] (Fig. 4). The sSMC was present in 45 of 100 lymphocyte-derived metaphases. FISH excluded the presence of SRY-specific 


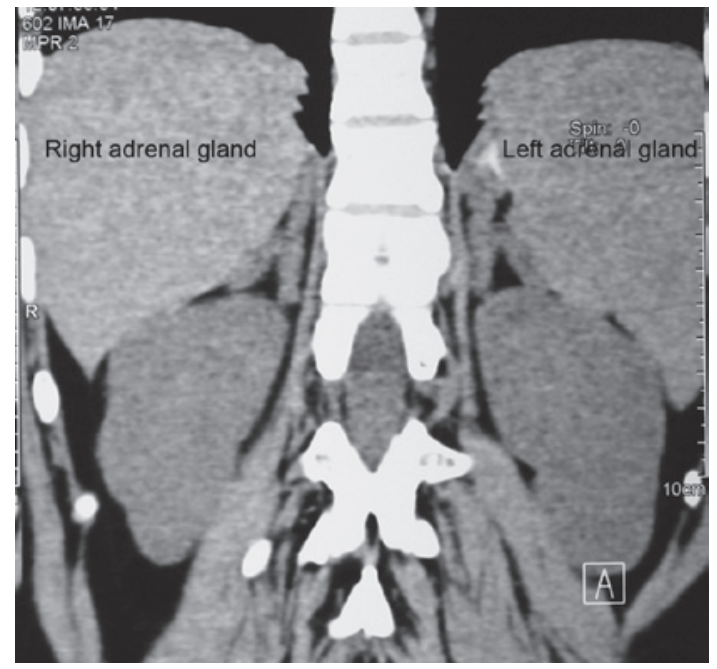

Figure 3. CT scan showed enlargement of left and right adrenal glands compared to the normal sizes.

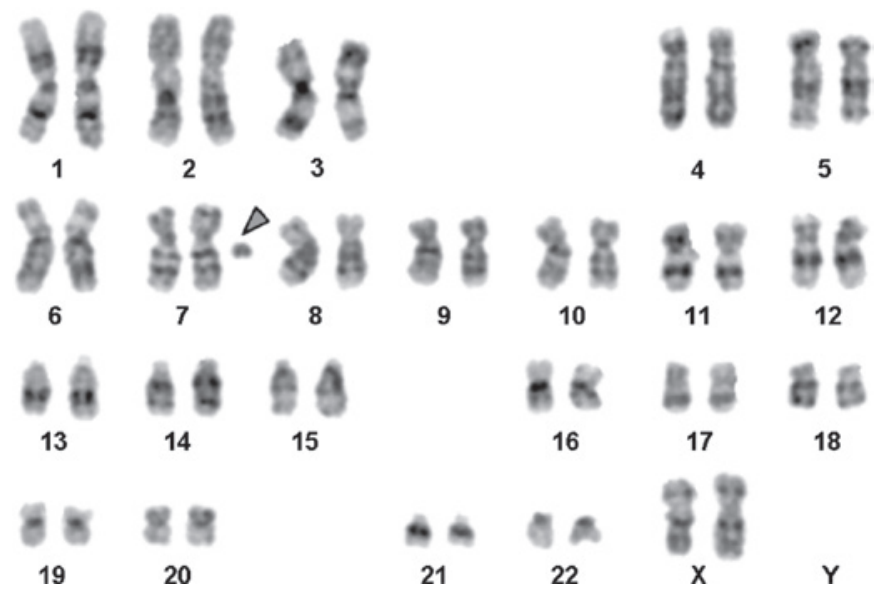

Figure 4. GTG-banding revealed a marker chromosome.

sequences (data not shown). The sSMC was further characterized by molecular cytogenetic studies which revealed a centric minute-shaped chromosome 7 [min(7)(:p11.1->q11.23:)] (Fig. 5). The karyotypes of the mother and the father were $46, X X$ and $46, X Y$, respectively.

Sequencing of the CYP21A2 gene revealed the homozygous mutation c.518T >A (p.Ile173Asn) in exon 4 (NM_000500.5; $\mathrm{ATG}=1$ ). Both parents are heterozygous for that mutation (Fig. 6).

\section{Discussion}

$\operatorname{sSMC}(7)$ is very rare and usually small in size. They consist of the centromere and small amounts of euchromatic material, a fact which also applies to our patient. Only 15 patients with sSMC originating from the proximal region of the long arm are described in the literature. Comparing the phenotype of cases reported, delay of speech is often reported (http://www. med.uni-jena.de/fish/sSMC/07.htm\#Start07).

The phenotypic spectrum associated with duplication of the 7q11.23 Williams-Beuren Syndrome (WBS) region has previously been delineated. In these patients, the main clinical feature is a moderate to severe expressed language delay (19).

\section{1) RP11-10F11 cep 7 \\ RP11-3N2}

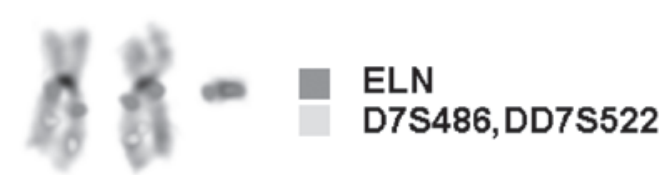

Figure 5. Molecular cytogenetic analysis revealed a ring chromosome $7[\mathrm{r}(7)]$ (p11.1q11.23 21.1).

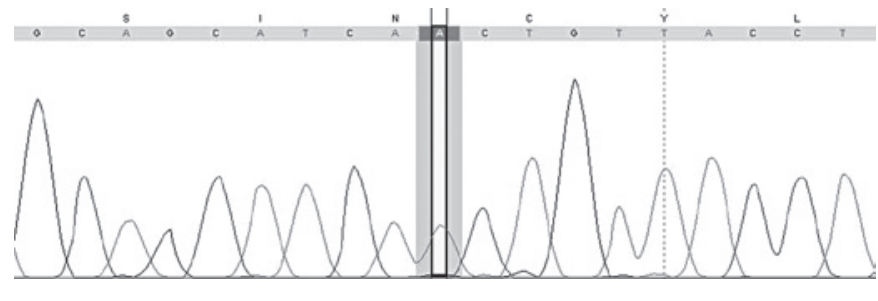

Figure 6. Homozygous mutation c.518T >A (p.Ile173Asn) in exon 4 of the CYP21A2 gene.

By contrast, subjects with deletion of the same interval have good communication competence, with a relative strength in verbal skill. These findings support the idea that this region contains genes that may affect speech performance in a dosedependent manner. Four genes (CALN1, STX1A, LIMK1 and CYLN), involved in brain development or function, have been identified (20). As was observed in our patient, facial anomalies are non-specific, but some traits are common to both ring chromosome $7[\mathrm{r}(7)]$ carriers and patients with WBS duplication, and thus they can be associated with $7 \mathrm{q}$ proximal region triplication. Our patient shares a prominent forehead, a triangular face, a high nasal bridge, normal eyes, thin lips, short philtrum and normal ears (21) with the other patients. By contrast, other aspects, such as hirsutism, were observed in our case and other cases as well (21). These features should be carefully sought when a new case of $\mathrm{r}(7)$ is discovered, since they could represent helpful clues to better delineate the $r(7)$ phenotype.

$\mathrm{CAH}$ is found in a wide range of clinical severity ranging from subtle hormone imbalance in adults to severe lifethreatening SW in newborns (22). Detection of the underlying mutations in the CYP21A2 gene encoding steroid 21-hydroxylase enzyme is helpful both for confirmation of diagnosis and management of CAH patients (22). Approximately 95\% of the mutated alleles in patients with steroid 21-OHD are generated by transfer of DNA sequences from CYP21A1P to CYP21A2 by gene conversion events (23). The remaining 5\% of the alleles show new/rare mutations due to random events (24). Most of these mutations are unique to individual families, but some are population-specific $(25,26)$. Different kinds of mutations result in different degrees of enzymatic impairment of P450c21, which result in varied phenotypes of CAH patients. A large number of mutations detected in the CYP21A2 gene have been characterized to prove their clinical relevance and 
impact on the $\mathrm{P} 450 \mathrm{c} 21$ protein. The residual enzyme activity is then measured towards both natural substrates (17-OHP and progesterone) and compared to the wild-type protein. The percentage of the residual enzyme activity is correlated with the clinical phenotype and subsequently mutations are classified as simple virilization, SW or non-classic types of AGS (27-31), with the change c.518T >A being a typical mutation for simple virilization.

To our knowledge, in this study, we present the first report of a female pseudohermaphroditism, classified as simple virilization form of 21-OHD, with an additional $\min (7(: \mathrm{p} 11.1->\mathrm{q} 11.23$ : $)$ and the homozygous mutation c.518T >A (p.Ile173Asn) in the CYP21A2 gene.

\section{Acknowledgements}

The authors thank Professor I. Othman, the Director General of Atomic Energy Commission of SYRIA (AECS), and Dr N. Mirali, Head of Molecular Biology and Biotechnology Department, for their support. This study was supported by the AECS, in parts by the DAAD (D/07/09624).

\section{References}

1. Liehr T, Claussen U and Starke H: Small supernumerary marker chromosomes (sSMC) in humans. Cytogenet Genome Res 107: $55-67,2004$.

2. Liehr T and Weise A: Frequency of small supernumerary marker chromosomes in prenatal, newborn, developmentally retarded and infertility diagnostics. Int J Mol Med 19: 719-731, 2007.

3. Liehr T: Small supernumerary marker chromosomes (sSMCs): a spotlight on some nomenclature problems. J Histochem Cytochem 57: 991-993, 2009.

4. Miyoshi O, Kondoh T, Taneda H, Otsuka K, Matsumoto T and Niikawa N: 47,XX,UPD(7)mat,r(7)pat/46,XX,UPD(7)mat mosaicism in a girl with Silver-Russell syndrome (SRS): possible exclusion of the putative SRS gene from a 7p13-q11 region. J Med Genet 36: 326-329, 1999.

5. Liehr T: Cytogenetic contribution to uniparental disomy (UPD). Mol Cytogenet 3: 8, 2010.

6. White PC, Tusie-Luna MT, New MI and Speiser PW: Mutations in steroid 21-hydroxylase (CYP21). Hum Mutat 3: 373-378, 1994

7. Speiser PW and White PC: Congenital adrenal hyperplasia. N Engl J Med 349: 776-788, 2003.

8. Kawaguchi H, O'hUigin C and Klein J: Evolutionary origin of mutations in the primate cytochrome P450c21 gene. Am J Hum Genet 50: 766-780, 1992 .

9. Levine LS, Zachmann M, New MI, Prader A, Pollack MS, O'Neill GJ, Yang SY, Oberfield SE and Dupont B: Genetic mapping of the 21-hydroxylase-deficiency gene within the HLA linkage group. N Engl J Med 299: 911-915, 1978.

10. Tajima T, Fujieda K and Fujii-Kuriyama Y: De novo mutation causes steroid 21-hydroxylase deficiency in one family of HLA-identical affected and unaffected siblings. J Clin Endocrinol Metab 77: 86-89, 1993.

11. White PC and Speiser PW: Congenital adrenal hyperplasia due to 21-hydroxylase deficiency. Endocr Rev 21: 245-291, 2000.

12. Jaaskelainen J, Levo A, Voutilainen R and Partanen J: Populationwide evaluation of disease manifestation in relation to molecular genotype in steroid 21-hydroxylase (CYP21) deficiency: good correlation in a well defined population. J Clin Endocrinol Metab 82: 3293-3297, 1997.

13. Krone N, Braun A, Roscher AA, Knorr D and Schwarz HP: Predicting phenotype in steroid 21-hydroxylase deficiency? Comprehensive genotyping in 155 unrelated, well defined patients from southern Germany. J Clin Endocrinol Metab 85: 1059-1065, 2000.

14. Claussen U, Michel S, Mühlig P, Westermann M, Grummt UW, Kromeyer-Hauschild K and Liehr T: Demystifying chromosome preparation and the implications for the concept of chromosome condensation during mitosis. Cytogenet Genome Res 98: 136-146, 2002.
15. Shaffer L, Slovak M and Cambell L (eds): ISCN (2009): An International System for Human Cytogenetic Nomenclature. S. Karger, Basel, 2009.

16. Nietzel A, Rocchi M, Starke H, Heller A, Fiedler W, Wlodarska I, Loncarevic IF, Beensen V, Claussen U and Liehr T: A new multicolor-FISH approach for the characterization of marker chromosomes: centromerespecific multicolor-FISH (cenMFISH). Hum Genet 108: 199-204, 2001.

17. Oliver-Bonet M, Liehr T, Nietzel A, Heller A, Starke H, Claussen U, Codina-Pascual M, Pujol A, Abad C, Egozcue J, Navarro $\mathrm{J}$ and Benet $\mathrm{J}$ : Karyotyping of human synaptonemal complexes by cenM-FISH. Eur J Hum Genet 11: 879-883, 2003.

18. Starke H, Nietzel A, Weise A, Heller A, Mrasek K, Belitz B, Kelbova C, Volleth M, Albrecht B, Mitulla B, Trappe R, et al: Small supernumerary marker chromosomes (SMC): genotypephenotype correlation and classification. Hum Genet 114: 51-67, 2003.

19. Berg JS, Brunetti-Pierri N, Peters SU, Kang SH, Fong CT, Salamone J, Freedenberg D, Hannig VL, Prock LA, Miller DT, Raffalli $\mathrm{P}$, et al: Speech delay and autism spectrum behaviors are frequently associated with duplication of the 7q11.23 WilliamsBeuren syndrome region. Genet Med 9: 427-441, 2007.

20. Lichtenbelt KD, Hochstenbach R, van Dam WM, Eleveld MJ, Poot $\mathrm{M}$ and Beemer FA: Supernumerary ring chromosome mosaicism: case report, investigation of the gene content, and delineation of the phenotype. Am J Med Genet Part A 132: 93-100, 2005.

21. Bertini V, Valetto A, Uccelli A, Bonuccelli A, Tarantino E, Taddeucci $\mathrm{G}$ and Simi P: Molecular cytogenetic characterization of a de novo mosaic supernumerary ring chromosome 7: report of a new patient. Am J Med Genet part A 146A: 2955-2959, 2008.

22. Dubey S, Idicula-Thomas S, Anwaruddin M, Saravanan C, Varma RR and Maitra A: A novel 9-bp insertion detected in steroid 21-hydroxylase gene (CYP21A2): prediction of its structural and functional implications by computational methods. J Biomed Sci 16: 3, 2009.

23. Higashi Y, Tanae A, Inoue $\mathrm{H}$ and Fujii-Kuriyama Y: Evidence for frequent gene conversion in the steroid 21-hydroxylase (P450c21) gene: implications for steroid 21-hydroxylase deficiency. Am J Hum Genet 42: 17-25, 1998.

24. Wedell A, Thilén A, Ritzén EM, Stengler B and Luthman H: Mutational spectrum of the steroid 21-hydroxylase gene in Sweden: implications for genetic diagnosis and association with disease manifestation. J Clin Endocrinol Metab 78: 1145-1152, 1994.

25. Billerbeck AE, Bachega TA, Frazatto ET, Nishi MY, Goldberg AC, Marin ML, Madureira G, Monte O, Arnhold IJ and Mendonca BB: A novel missense mutation, G424S, in Brazilian patients with 21-hydroxylase deficiency. J Clin Endocrinol Metab 84: 2870-2872, 1999.

26. Barbaro M, Lajic S, Baldazzi L, Balsamo A, Pirazzoli P, Cicognani A, Wedell A and Cacciari E: Functional analysis of two recurrent aminoacid substitution in the CYP21 gene from Italian patients with congenital adrenal hyperplasia. J Clin Endocrinol Metab 89: 2402-2407, 2004.

27. Database of CYP21A2 by human Cytochrome P450 (CYP) Allele Nomenclature Committee [http://www.imm.ki.se/CYP alleles/cyp21.htm].

28. Robins T, Bellanne-Chantelot C, Barbaro M, Cabrol S, Wedell A and Lajic S: Characterization of novel missense mutations in CYP21 causing congenital adrenal hyperplasia. J Mol Med 85: 247-255, 2007.

29. Menassa R, Tardy V, Despert F, Bouvattier-Morel C, Brossier JP, Cartigny M and Morel Y: p.H62L, a rare mutation of the CYP21 gene identified in two forms of 21-hydroxylase deficiency. J Clin Endocrinol Metab 93: 1901-1908, 2008.

30. Soardi FC, Barbaro M, Lau IF, Lemos-Marini SHV, Baptista MTM, Guerra-Junior G, Wedell A, Lajic S and de Mello MP: Inhibition of CYP21A2 enzyme activity caused by novel missense mutations identified in Brazilian and Scandinavian patients. J Clin Endocrinol Metab 93: 2416-2420, 2008.

31. Riepe FG, Hiort O, Grtzinger J, Sippell WG, Krone N and Holterhus PM: Functional and structural consequences of a novel point mutation in the CYP21A2 gene causing congenital adrenal hyperplasia: potential relevance of helix $\mathrm{C}$ for $\mathrm{P} 450$ oxidoreductase-21-hydroxylase interaction. J Clin Endocrinol Metab 93: 2891-2895, 2008. 